\title{
Direito à educação e valorização profissional O papel do Estado e da sociedade
}

\author{
Juçara Dutra Vieira*
}

\begin{abstract}
RESUMO: Este trabalho analisa a valorização dos profissionais da educação básica, partindo do pressuposto de que é uma das condições e, ao mesmo tempo, uma das respostas à educação como direito. Essa relação ocorre na dinâmica social, mediada pelo Estado e, por isso, suscetível a contradições, avanços e recuos. O corte temporal é de três décadas, partindo da Constituição Federal de 1988, principal marco da legislação brasileira.
\end{abstract}

Palavras-chave: Educação como direito. Estado e sociedade. Valorização profissional.

\section{Introdução}

$\mathrm{H}$ á uma diferença de enfoque entre as expressões "direito à educação" e "educação como direito", embora ambas representem passos importantes da sociedade na construção de seus referenciais civilizatórios. $\mathrm{O}$ "direito à educação" é a possibilidade de acessar um bem, um valor, um componente da socialização humana. No Brasil, educação é direito público subjetivo, mecanismo que permite ao sujeito apropriar-se da norma geral, que é abstrata, e aplicá-la à sua situação concreta. De acordo com Duarte (2004), “a maneira de fazê-lo é acionando as normas jurídicas (direito objetivo) e transformando-as em seu direito (direito subjetivo)." (p. 113, grifo da autora). Desse modo, o direito público subjetivo é um instrumento jurídico que propicia o controle da ação do Estado e a cobrança de suas eventuais omissões.

\footnotetext{
* Doutora em educação. Professora aposentada da rede pública do Rio Grande do Sul. Foi vice-presidente da Internacional da Educação (IE) (2004-2015) e presidente da Confederação Nacional dos Trabalhadores em Educação (2002-2008). Atualmente é membro do Comitê Editorial da Revista Retratos da Escola. Porto Alegre/RS - Brasil. E-mail: <judvieira@gmail.com>.
} 
A expressão "educação como direito" consiste na transformação do direito individual em princípio fundante da sociedade, o que o torna extensivo a todos. Desse modo, ninguém mais necessita reivindicar o direito nem recorrer a mecanismos legais para obtê-lo. Simples assim? Evidentemente, não. A materialização do princípio depende do convencimento social e a sociedade não é um conjunto homogêneo de pessoas e de interesses. Ao mesmo tempo, a transformação do princípio em política requer a mediação do Estado, cujos agentes também se movem em complexas redes de relações.

Bobbio ensina que "os direitos do homem são, indubitavelmente, um fenômeno social" (1992, p. 68), cuja evolução ocorreu de três modos: aumento da quantidade de bens merecedores de tutela; extensão de alguns direitos típicos a sujeitos diversos do homem; passagem da ideia de homem para suas reais e diversas maneiras de ser em sociedade. Para o autor, a transição do que chama de liberdades negativas - de religião, opinião, imprensa etc. - para os direitos políticos e sociais "requerem uma intervenção direta do Estado." (p. 68). O raciocínio considera que os direitos de liberdade nascem contra o superpoder do Estado, enquanto os direitos sociais exigem exatamente o contrário, ou seja, a ampliação dos poderes do Estado.

O parágrafo anterior sustenta que a evolução dos direitos do homem foi impulsionada pela ampliação de bens a serem protegidos e, também, pelo reconhecimento das diversidades no homem concreto. Essa perspectiva permite que se pense a educação como um valor acrescido aos bens, historicamente, sob a tutela do Estado, mas não somente isso. A evolução considera as mudanças qualitativas produzidas pela ampliação dos sujeitos que são portadores de novas demandas.

A abordagem da temática da valorização profissional parte deste pressuposto: a relação intrínseca entre educação e direito. No Brasil, o art. 205 da Constituição Federal (CF) expressa: "A educação, direito de todos e dever do Estado e da família, será promovida e incentivada com a colaboração da sociedade, visando ao pleno desenvolvimento da pessoa, seu preparo para o exercício da cidadania e sua qualificação para o trabalho." (BRASIL, 1988). Os princípios que norteiam esse dispositivo constitucional, contidos no art. 206, abarcam, entre outros: igualdade de condições de acesso e permanência na escola; pluralismo de ideias e concepções pedagógicas; gestão democrática e gratuidade do ensino público; e garantia de padrão de qualidade. Em relação à valorização dos profissionais da educação escolar, os princípios expressos na CF incluem planos de carreira e Piso Salarial Profissional Nacional (PSPN). A redação desses dispositivos foi dada pela Emenda Constitucional no 53, de 2006 (BRASIL, 2006) e pela Lei nº 11.738, de 2008, que instituiu o piso salarial dois anos depois (BRASIL, 2008).

Nas duas décadas que separam a aprovação do texto da Constituição Federal e a instituição do PSPN, a sociedade brasileira foi desafiada a consolidar o direito à educação para a população brasileira, cada vez maior, mais urbanizada, mais suscetível às mudanças do mundo do trabalho e seus contextos econômicos, sócio-políticos e culturais. Ao 
mesmo tempo, a emergência de novos sujeitos portadores de direitos - sejam os historicamente negados a diversos estratos sociais, sejam os alimentados pelas lutas feministas, multiculturais, ambientais e outras - passaram a tensionar o Estado pela adoção da educação como direito, isto é, como política estruturante da igualdade na diversidade.

\section{Valorização profissional e a educação como direito}

O Brasil emergia de uma ditadura civil-militar de mais de 20 anos quando foi promulgada a Constituição de 1988. O ambiente de luta por retomada de direitos civis foi um dos fatores que concorreu para retardar a aplicação das políticas neoliberais inspiradas nos governos de Thatcher (Inglaterra) e Reagan (Estados Unidos) já adotadas no continente, como no caso do Chile. No ano seguinte, em 1989, o Brasil elegeria Fernando Collor de Mello na primeira eleição direta para presidente da república pós-ditadura. A gestão foi interrompida por um processo de impedimento, assumindo o vice-presidente, Itamar Franco, para completar a gestão. Nesse período, foi retomado um antigo debate protagonizado pela Confederação Nacional dos Trabalhadores em Educação (CNTE) em torno da valorização profissional.

No cenário internacional, a Organização das Nações Unidas para a Educação, a Ciência e a Cultura (Unesco) tentava implementar políticas de combate ao analfabetismo e de acesso à educação, comprometendo vários países em torno de metas expressas na Declaração Mundial sobre Educação para Todos, documento produzido na Conferência de Jontiem, Tailândia, em 1990. As recomendações internacionais se desdobraram em conferências nacionais com vistas à construção de planos decenais de educação. Foi nesse contexto de discussão sobre garantias de direitos que vários atores sociais ${ }^{2}$, entre os quais a CNTE, assinaram o Acordo Nacional de Educação para Todos. O documento enfatizava:

A qualidade do ensino ministrado pela escola básica e seu sucesso na tarefa de formar cidadãos capazes de participar plenamente da vida política, social, cultural e econômica do País relaciona-se estritamente à formação, à atualização, às condições de trabalho e à remuneração dos docentes. (BRASIL, 1994, p. 22).

Baseado nessa lógica, o Acordo previa uma política nacional de formação que considerasse a variedade de situações existentes no Brasil; a implantação de um piso salarial profissional nacional do magistério de, no mínimo, $\mathrm{R} \$ 300,00$, com garantia de seu poder aquisitivo em 1ํ de julho de 1994, como remuneração total no início da carreira; e o acesso a um novo regime de trabalho de 40 horas semanais com $25 \%$ do tempo destinado a trabalho extraclasse. 
O Acordo vigoraria a partir de 15 de outubro de 1995, data escolhida para celebrar o "dia do professor". Entretanto, as eleições de 1994 conduziram Fernando Henrique Cardoso à presidência da república, mandato que seria renovado nas eleições de 1998. O novo governo desconsiderou o processo e os compromissos firmados, inviabilizando as políticas que vigorariam no decênio. Os retrocessos não podem ser entendidos, simplesmente, como uma retaliação aos educadores, mas como parte de uma política para a educação e para a sociedade brasileira.

O governo Cardoso elegeu um projeto de desenvolvimento baseado na redução do papel do Estado como indutor do projeto de desenvolvimento. Assim, a ideia de privatização de estatais, como a Vale do Rio Doce e a Telebras, não ficou circunscrita a produtos e serviços na esfera da economia. Na mesma lógica, o governo formulou uma proposta de reforma administrativa, distinguindo quatro setores no aparelho de Estado: "núcleo estratégico", correspondente às altas funções de governo que definem as leis e as políticas públicas; "atividades exclusivas" que incluem cobrança e fiscalização de impostos, polícia, entre outros; "serviços não exclusivos", onde o Estado atua simultaneamente com outras organizações públicas não estatais e privadas, como educação e saúde; e "produção de bens e serviços para o mercado", caracterizado pelas "atividades econômicas voltadas para o lucro que ainda permanecem no aparelho do Estado como, por exemplo, as do setor de infraestrutura." (BRASIL, 1995, p. 42).

A lógica de transferência de recursos públicos por meio de delegação de competências logo se expressaria na área da educação. A regulamentação da educação profissional, por meio do Decreto n 2.208 , de 1997, iniciou um período de encolhimento da rede pública, pois, ao financiar o setor privado, propiciou a multiplicação da oferta de vagas em instituições particulares com amparo no art. $4^{\circ}$,

$\S 1^{\circ}$ As instituições federais e as instituições públicas e privadas sem fins lucrativos, apoiadas financeiramente pelo Poder Público, que ministram educação profissional deverão, obrigatoriamente, oferecer cursos profissionais de nível básico em sua programação, abertos a alunos das redes públicas e privadas de educação básica, assim como a trabalhadores com qualquer nível de escolaridade. (BRASIL, 1997).

Os efeitos dessa norma só cessaram com a edição do Decreto nº 5.154, de 2004 que reorientou a política para a educação profissional. A concepção de Estado permitiu, igualmente, a expansão desordenada da educação superior privada pela falta de políticas para a educação pública. O tratamento dispensado pelos dois governos de Fernando Henrique Cardoso à educação básica não foi muito diferente. Por se tratar de uma etapa menos atraente ao mercado, a privatização cedeu lugar à focalização na educação fundamental, cuja faixa etária guardava correspondência com a obrigatoriedade escolar, então dos 7 aos 14 anos. Nesse cenário, a valorização profissional não tinha sentido, pois 
a educação não se enquadrava nas atividades estratégicas ou exclusivas de Estado e as políticas educacionais não tinham como centralidade o conceito de direito.

Em 2002, Luiz Inácio Lula da Silva foi eleito presidente do Brasil com o apoio de amplos setores da esquerda, de movimentos sociais, sindicais e estudantis, depositários de muitas expectativas em relação à ampliação dos direitos sociais. No início da gestão, entretanto, ocorreu um impasse provocado pela reforma da previdência no serviço público. A iniciativa teve o apoio de setores conservadores e resistência do setor público, incluindo parte importante da base social que apoiara a eleição de Lula. A segunda disputa ocorreu em 2005, quando o governo foi duramente atingido com o escândalo que ficou conhecido como "mensalão". O movimento social ${ }^{3}$ reagiu à ameaça de impedimento do presidente da república. Ao fazer a defesa, porém, tratou de pressionar o governo por pautas voltadas para a ampliação dos direitos da classe trabalhadora.

A reivindicação do movimento supunha o aumento de protagonismo dos trabalhadores não apenas no acolhimento de suas pautas, mas, também, na forma de transformá-las em políticas públicas. De acordo com Cárcova (2008), o Estado capitalista perdeu o papel cultural que manteve por três séculos. Por isso, impõe-se uma nova agenda de discussão sobre um "Estado democrático de novo tipo [que] deve privilegiar, organicamente, a participação popular em todos os assuntos de interesse público, habilitando, em tudo quanto seja possível, a realização autogestionária da política." (p. 103).

O Governo Lula não levou ao pé da letra essa recomendação, que exigiria, por exemplo, o debate social sobre o orçamento público. Disseminou, porém, o mecanismo das conferências para a definição de várias políticas públicas pertinentes a: gênero, juventude, saúde, assistência social, idosos, segurança alimentar, comunicação, arranjos produtivos e outros. Na área da educação, a primeira conferência foi tardia, após, inclusive, a segunda edição de várias outras que abordaram diferentes temáticas. A Conferência Nacional de Educação (Conae) 2010 assumiu o debate sobre o sistema nacional articulado de educação e o Plano Nacional de Educação (PNE). No documento preliminar, a comissão organizadora do evento enfatizou a necessidade de "mobilização dos segmentos sociais para um amplo debate educacional em uma perspectiva inclusiva e de desenvolvimento social." (QUEIROZ; GOMES, 2009, p. 8).

A construção do sistema nacional de educação é estratégica para o estabelecimento de políticas públicas, especialmente pela organização descentralizada da educação básica e, em decorrência disso, pela divisão de responsabilidades dos entes federados. Uma situação emblemática é a do PSPN, aprovado pela Lei no 11.738 , de 2008. Já no Império, D. Pedro I tentara fixar um vencimento médio, ao criar escolas de primeiras letras em cidades, vilas e locais mais populosos do país. A Lei de 15 de outubro de 1827 previa:

Art. $3^{\circ}$. Os presidentes, em Conselho, taxarão interinamente os ordenados dos Professores, regulando-os de 200\$000 a 500\$000 anuais, com atenção às circunstâncias 
da população e carestia dos lugares, e o farão presente a Assembleia Geral para a aprovação. (BRASIL, 1827).

O texto relacionava, explicitamente, a implantação da medida com a situação socioeconômica da população, assim como o arbítrio do legislativo local nessas definições. Entretanto, a instabilidade do Império e a descontinuidade das relações com as províncias inviabilizaram a iniciativa. A ideia de um piso salarial seria retomada várias vezes, especialmente em períodos de debates mais democráticos, como o da elaboração da Constituição Federal e da formulação de proposta de LDB no final dos anos 1980 e início dos anos 1990, aprovada em 1996, já sob a influência do governo de Fernando Henrique Cardoso. O Acordo de 1994, já referido, foi frustrado, exigindo novas estratégias de mobilização e de convencimento social para voltar à cena.

A CNTE retomou o debate no contexto da discussão da ampliação do financiamento da educação, seja por meio da transformação do Fundef ${ }^{4}$ em Fundeb $^{5}$, seja pela elevação do percentual do Produto Interno Bruto (PIB) para a educação. O Fundeb representou um ganho qualitativo na medida em que estendeu seu alcance à educação infantil e à média, sedimentando a ideia de educação básica como direito, não apenas a etapa fundamental, atendida pelo Fundef. Este foi um importante elemento para o convencimento das várias esferas de governo, dos parlamentos e da sociedade sobre a viabilidade do PSPN, pois parte de seu financiamento é viabilizada pelos recursos do Fundeb.

A formação dos profissionais da educação é outro componente da valorização profissional intrinsecamente relacionada à educação como direito. Uma medida importante do governo Lula foi a de responsabilizar também a União pela formação dos educadores, até então sob encargo dos estados. A vigência do novo PNE, aprovado pela Lei n⿳⺈ 13.005/2014, dá um passo importante no sentido de integrar programas de formação federais e ações já desenvolvidas pelos estados e municípios. As metas 15 e 16 do PNE preveem, respectivamente, que todos os professores e as professoras da educação básica possuam formação específica de nível superior, obtida em curso de licenciatura na área de conhecimento em que atuam; e que 50\% tenham acesso a cursos de pós-graduação e que todos tenham a garantia de formação continuada em sua área de atuação, considerando as necessidades, demandas e contextualizações dos sistemas de ensino.

Para estabelecer tais contextualizações, é necessário repensar a própria escola como espaço educativo. Dessa percepção resulta a ideia - transformada em política pública - de considerar que os funcionários de escola também exercem funções educativas. Foi com base nessa compreensão que a CNTE propôs a profissionalização dos funcionários em cursos técnicos de nível médio e, mais recentemente, cursos tecnológicos de nível superior. A experiência do Profuncionário produziu bons resultados não só na construção da identidade profissional, mas também na concepção de uma escola democrática, com novos saberes e novas práticas. O Profuncionário é um "programa indutor 
de formação profissional em serviço dos funcionários da educação básica pública, em habilitação compatível com sua atividade educativa, na modalidade da Educação a Distância (EAD)." (BRASIL, 2016).

A educação como direito da sociedade corresponde ao dever do Estado em assegurá-la. Nesse sentido, as carreiras são indispensáveis, embora não sejam exclusivas de Estado, como já abordado neste texto. De um lado, elas representam importante aspecto da profissionalização na medida em que estimulam a dedicação ao trabalho. De outro, representam o direito da sociedade em contar com um conjunto orgânico de trabalhadores estáveis na função pública, ou seja, sem risco de descontinuidades prejudiciais ao funcionamento das escolas e do sistema. O Conselho Nacional de Educação (CNE) deu importante contribuição à profissionalização, estabelecendo diretrizes nacionais de carreira para os profissionais da educação, ainda que o tenha feito, separadamente, para professores ${ }^{6}$ e para funcionários da educação ${ }^{7}$. Em vários estados brasileiros, as carreiras já são unificadas.

Os componentes da valorização profissional elencados neste texto - formação inicial e continuada, carreira e salário - constituem um conjunto de condições indissociáveis para o exercício da profissão. É de se perguntar, porém, se esses requisitos são suficientes para constituir o sujeito que se dedica à educação escolar. Baseada em vários autores, Costa (1995) acredita que

Profissionalização é um processo historicamente específico desenvolvido por algumas ocupações em um determinado tempo e não um processo que certas ocupações devem sempre realizar devido a suas qualidades essenciais; é uma forma de controle político do trabalho, conquistado por um grupo social, em dado momento histórico. (p. 89, grifo da autora).

A construção da identidade do profissional da educação é, assim, um fenômeno social. O reconhecimento da sociedade é determinado pela relevância que ela percebe naquele trabalho. Ao mesmo tempo, as relações que se estabelecem em uma área como a educação - que é ao mesmo tempo ciência e prática social - são permeadas por ambas. $\mathrm{O}$ modo como o educador vê o mundo, o projeto de sociedade que vislumbra e os valores que cultiva estão presentes no seu trabalho. Conceitos como inclusão, gestão democrática, identidade de gênero, cultura multirracial e igualdade na diversidade são constitutivos de suas vivências e experiências. Por isso, dos próprios saberes profissionais.

\section{Considerações finais}

Nos últimos 30 anos, a educação brasileira foi desafiada a superar as políticas educacionais de orientação neoliberal e teve avanços institucionais e políticos. Promoveu o debate e pensou alguns mecanismos para a construção do sistema nacional de educação; 
investiu na expansão da educação superior pública; ampliou a obrigatoriedade da educação; aumentou os recursos destinados à educação; melhorou os índices de alfabetização; e investiu na educação profissional para jovens e adultos.

Em termos de valorização profissional, o PSPN representou uma conquista histórica e foram instituídas várias políticas relacionadas à formação, às carreiras e às condições de trabalho. Contudo, como constatam Gatti e Barreto (2009),

salários pouco atraentes [...] e planos de carreira estruturados de modo a não oferecer horizontes claros, promissores e recompensadores no exercício da docência interferem nas escolhas profissionais dos jovens e na representação e valorização social da profissão de professor. (p. 256).

Aprovada em 2008, a lei que instituiu o PSPN não é cumprida pela maior parte dos estados e municípios brasileiros. Isso deixa distante a possibilidade de equivalência salarial com outras profissões de formação equivalente, como preconiza o PNE. A formação continuada não pode mais prescindir de políticas, como o ano sabático, de inclusão dos profissionais na área de tecnologias da informação e da comunicação (TIC) e de iniciação à pesquisa. A carreira precisa induzir à dedicação exclusiva e as condições de trabalho devem assegurar a saúde e o bem-estar no ambiente profissional.

Essas pautas remetem, novamente, ao sentido da valorização profissional como parte de um processo de ampliação de direitos. Assim, a formação precisa responder às expectativas geracionais em que "a transição do sistema educacional para o mundo do trabalho e o processo de educação para toda a vida assumem maior relevância." (POCHMANN, 2010, p. 95). Melhores salários não podem estar condicionados à meritocracia, mas à obtenção de padrões de qualidade para todos. As lutas por valorização salarial precisam caminhar juntas com a disputa de investimentos públicos compatíveis com as metas de elevação de escolaridade, de aumento de anos de permanência na escola e de educação ao longo da vida.

Tratou-se, neste texto, de estabelecer um nexo entre direito à educação e valorização profissional não apenas como uma (legítima) reivindicação corporativa. A intenção foi mostrar que essa preocupação deve ser da sociedade e sua concretização uma atribuição do Estado. Tentou-se evidenciar que os agentes do Estado, que são os governos, só são permeáveis a essas demandas se concebem a educação como um direito. Por sua vez, o conceito de direito é uma construção histórica que ganha significado no contexto em que se realiza. Por isso, vale a pena lembrar o que disseram Marx e Engels: "A teoria materialista da mudança das circunstâncias e da educação esquece que as circunstâncias fazem mudar os homens e que o educador necessita, por sua vez, ser educado." (2006, p. 35). 


\section{Notas}

1 Entidades que assinaram o Acordo Nacional de Educação para Todos: Confederação Nacional dos Trabalhadores em Educação (CNTE), Conselho Nacional dos Secretários de Educação (Consed), Conselho de Reitores das Universidades Brasileiras (CRUB), Fórum dos Conselhos de Educação, Ministério da Educação e do Desporto e União Nacional dos Dirigentes Municipais de Educação (Undime).

2 Tomaram posição contra o impedimento diversas organizações sindicais e estudantis, entidades ligadas à área da educação, movimentos sociais e expressões da intelectualidade e da cultura brasileiras.

3 Fundo de Manutenção e Desenvolvimento do Ensino Fundamental de Valorização do Magistério, instituído pela Emenda Constitucional no 14/1996, e regulamentado pela Lei no 9.424/1996.

4 Fundo de Manutenção e Desenvolvimento da Educação Básica e de Valorização dos Profissionais da Educação, criado pela Emenda Constitucional no 53/2006 e regulamentado pela Lei nº 11.494/2007.

5 Resolução nํㅡ 2, de 28 de maio de 2009 - Fixa as Diretrizes Nacionais para os Planos de Carreira e Remuneração dos Profissionais do Magistério da Educação Básica Pública, em conformidade com o artigo $6^{0}$ da Lei nº 11.738, de 16 de julho de 2008, e com base nos artigos 206 e 211 da Constituição Federal, nos artigos 8요, § 1ㅜㅡ, e 67 da Lei no 9.394, de 20 de dezembro de 1996, e no artigo 40 da Lei no 11.494, de 20 de junho de 2007.

6 Resolução no 5, de 3 de agosto de 2010 - Fixa as Diretrizes Nacionais para os Planos de Carreira e Remuneração dos Funcionários da Educação Básica Pública.

\section{Referências}

BOBBIO, Norberto. A era dos direitos. Tradução de Carlos Nelson Coutinho. Rio de Janeiro: Editora Campus, 1992.

BRASIL. Lei de 15 de outubro de 1827. Manda crear escolas de primeiras letras em todas as cidades, vilas e lugares populosos do Império. CLBR, Rio de Janeiro, 1827. Disponível em: <http://www. planalto.gov.br/ccivil_03/leis/LIM/LIM-15-10-1827.htm>. Acesso em: 5 maio 2016.

Federal, 1988.

Constituição (1988). Constituição da República Federativa do Brasil. Brasília, DF: Senado

. Acordo Nacional de Educação para Todos. Brasília, DF: Ministério da Educação, 1994.

. Presidência da República. Plano diretor da reforma do aparelho do estado. Brasília, DF:

Presidência da República/Câmara da Reforma do Estado, 1995. Disponível em: <www.bresserpereira. org.br/documents/mare/planodiretor/planodiretor.pdf $>$. Acesso em: 3 maio 2016.

Emenda Constitucional no 14, de 12 de setembro de 1996. Modifica os arts. 34, 208, 211 e 212 da Constituição Federal e dá nova redação ao art. 60 do Ato das Disposições constitucionais Transitórias. Diário Oficial da União, Brasília, DF, 13 set. 1996a.

Lei nº 9.424, de 24 de dezembro de 1996. Dispõe sobre o Fundo de Manutenção e Desenvolvimento do Ensino Fundamental e Valorização do Magistério. Diário Oficial da União, Brasília, DF, 26 dez. 1996b.

Decreto $n^{\circ}$ 2.208, de 17 de abril de 1997. Regulamenta o § $2^{\circ}$ do art. 36 e os arts. 39 a 42 da Lei Federal no 9.394/96, que estabelece as Diretrizes e Bases da Educação Nacional. Diário Oficial da União, Brasília, DF, 18 abr. 1997. 
. Decreto $n^{\circ}$ 5.154, de 23 de julho de 2004. Regulamenta o $\S 2^{2}$ do art. 36 e os arts. 39 a 41 da Lei no 9.394, de 20 de dezembro de 1996, que estabelece as diretrizes e bases da educação nacional, e dá outras providências. Diário Oficial da União, Brasília, DF, 2004.

. Emenda Constitucional no 53, de 19 de dezembro de 2006. Dá nova redação aos arts. 7º 23, 30, 206, 208, 211 e 212 da Constituição Federal e ao art. 60 do Ato das Disposições Constitucionais Transitórias. Diário Oficial da União, Brasília, DF, 9 mar. 2006.

. Lei no 11.494, de 20 de junho de 2007. Regulamenta o Fundo de Manutenção e Desenvolvimento da Educação Básica e de Valorização dos Profissionais da Educação - FUNDEB, de que trata o art. 60 do Ato das Disposições Constitucionais Transitórias; altera a Lei no 10.195 , de 14 de fevereiro de 2001; revoga dispositivos das Leis nos 9.424 , de 24 de dezembro de 1996, 10.880, de 9 de junho de 2004, e 10.845, de 5 de março de 2004; e dá outras providências. Diário Oficial da União, Brasília, DF, 21 jun. 2007.

. Lei no 11.738, de 16 de julho de 2008. Regulamenta a alínea "e" do inciso III do caput do art. 60 do Ato das Disposições Constitucionais Transitórias, para instituir o piso salarial profissional nacional para os profissionais do magistério público da educação básica. Diário Oficial da União, Brasília, DF, 17 jul. 2008.

. Lei no 13.005, de 25 de junho de 2014. Aprova o Plano Nacional de Educação - PNE e dá outras providências. Diário Oficial da União, Brasília, DF, 2014.

. Ministério da Educação. Profuncionário - Apresentação. Disponível em: <http://portal.mec.gov. br/component/content/article?id=12365 >. Acesso em: 5 maio 2016.

CÁRCOVA, Carlos Maria. Estado social de direito e radicalidade democrática. In: GENRO, Tarso et al. O mundo real: socialismo na era pós-liberal. Porto Alegre: L \& PM, 2008.

COSTA, Marisa C. Vorraber. Trabalho docente e profissionalismo: uma análise sobre gênero, classe e profissionalismo no trabalho de professoras e professores de classes populares. Porto Alegre: Sulina, 1995.

DUARTE, Clarice Seixas. Direito público subjetivo e políticas educacionais. São Paulo Perspec., v. 18, n. 2, p. 113-118, 2004.

GATTI, Bernardete Angelina; BARRETTO, Elba Siqueira de Sá. Professores do Brasil: impasses e desafios. Brasília, DF: Unesco, 2009.

MARX, Karl; ENGELS, Friedrich. Textos sobre educação e ensino. Tradução de Rubens Eduardo Frias. 5. ed. São Paulo: Centauro, 2006.

ORGANIZAÇÃO DAS NAÇÕES UNIDAS PARA A EDUCAÇÃO, A CIÊNCIA E A CULTURA (UNESCO). Educação para Todos no Brasil. Disponível em: <http://www.unesco.org/new/pt/brasilia/ education/education-for-all/>. Acesso em: 3 maio 2016.

POCHMANN, Marcio. Desenvolvimento, trabalho e renda no Brasil: avanços recentes no emprego e na distribuição dos rendimentos. São Paulo: Editora Fundação Perseu Abramo, 2010. (Coleção Brasil em Debate, v. 2).

QUEIROZ, A. C.; GOMES, L. (Orgs.). Conferência Nacional de Educação (Conae) 2010: reflexões sobre o Sistema Nacional Articulado de Educação e o Plano Nacional de Educação. Brasília, DF: INEP, 2009. 


\section{The right to education and professional development The role of the state and society}

ABSTRACT: This paper analyzes the appreciation of the professionals in basic education, from the presumption that it is one of the conditions and at the same time, one of the answers to education as a right. This relationship occurs in social dynamics, mediated by the state and therefore susceptible to contradictions, advances and retreats. The period of time under consideration is three decades, starting with the 1988 Federal Constitution, a major landmark in Brazilian law.

Keywords: Education as a right. State and society. Professional development.

\section{Droit à l'éducation et valorisation professionnelle Le rôle de l'Etat et de la société}

RÉSUMÉ: Ce travail analyse la valorisation des professionnells de l'éducation basique, en partant du présupposé selon lequel elle est une des conditions, et en même temps, une des réponses à l'éducation comme droit. Cette relation s'effectue dans la dynamique sociale, médiée par l'Etat et est donc sensible aux contradictions, aux progrés et aux reculs. Cette analyse fut effectuée sur trois décennies, à partir de la Constitution Fédérale de 1988, principal repére de la législation brésilienne.

Mots-clés: Education comme droit . Etat et société. Valorisation professionnelle.

\section{Derecho a la educación y valoración profesional El papel del Estado y de la sociedad}

RESUMEN: Este trabajo analiza la valoración de los profesionales de la educación básica a partir de la premisa de que es una de las condiciones y, a la vez, una de las respuestas a la educación como derecho. Esa relación ocurre en la dinámica social, mediada por el Estado y, precisamente por ello, susceptible a contradicciones, avances y retrocesos. El recorte temporal es de tres décadas a partir de la Constitución Federal de 1988, principal marco de la legislación brasileña.

Palabras clave: Educación como derecho. Estado y sociedad. Valoración profesional. 